\title{
INVESTIGACIÓN/RESEARCH
}

Recibido: 07/08/2014 Aceptado: 015/09/2014 Publicado: 15/11/2014

\section{ORANGE IS THE NEW BLACK. UNA VISIÓN ANTROPOLÓGICA}

Javier García López ${ }^{\mathbf{1}}$ : Universidad a Distancia de Madrid. España. javier.garcia@udima.es

Alicia López Balsas: Universidad Rey Juan Carlos. España.

alicialb@prisatv.com

\section{RESUMEN:}

La investigación que se propone es un análisis cualitativo sobre la serie de ficción Orange is the new black, que muestra cómo es la vida en las cárceles para mujeres de Estados Unidos. Es un relato sobre una historia real, la de Piper Kerman, quien experimenta cómo en unos instantes cambia su vida debido a un asunto de drogas en el que se vio envuelta en el pasado. Por medio de un exhaustivo examen de los componentes de la narración, en este trabajo vamos a conocer cómo esta serie de ficción forja una perspectiva antropológica sobre ciertos probemas socioculturales como el lesbianismo, la corrupción, el poder y los abusos que su ejercicio conlleva. La ética y la moral, constructos culturales universales en la sociedad occidental se ponen en entredicho. En Orange is the new black las acciones de los individuos y sus efectos únicamente tienen sentido cuando los relacionamos con su contexto concreto.

PALABRAS CLAVE: Orange is te new black - Poder - Corrupción - Lesbianismo Serie de ficción

\footnotetext{
${ }^{1}$ Javier García López: Doctor en Comunicación. Actualmente es Profesor Adjunto en la Universidad a Distancia de Madrid, donde imparte las asignaturas Teoría de la Publicidad, Opinión Pública e Historia de la Comunicación Social.

Correo: javier.garcia@udima.es
} 


\section{ORANGE IS THE NEW BLACK. AN ANTHROPOLOGICAL PERSPECTIVE}

\section{ABSTRACT}

The proposed research is a qualitative analysis of the fiction series Orange is the new Black, this shows how life is in women's prisons in the United States. It is a tale about a true story, the Piper Kerman's true story, who experienced how her life changed in a moment because of a drug deal in which he was involved in the past. In this work we are going to know how this series of fiction built an anthropological perspective on certain sociocultural issues as lesbianism, corruption, power abuse and its implementation. All through a comprehensive review of the components of the story. Ethics and morality, universal cultural constructs in Western society, are questioned. The actions of individuals and their effects only make sense when relate to their specific context in Orange is the new black.

KEYWORDS: Orange is the new black - Power - Corruption - Lesbianism - Fiction series

\section{Introducción}

Las series de ficción de las grandes productoras norteamericanas se han convertido en los últimos años en objetos de consumo de masas. Cada vez que se estrena uno de estos objetos comerciales, se convierte en un fenómeno llamado de culto debido a su popularidad. Pero dicha popularidad reside en uno o varios elementos narrativos que constituyen una novedad o idea original que, a su vez, choca con lo establecido hasta el momento. Podemos decir que son series de calidad, entendiendo como tal a la ficción televisiva valorada en términos formales y en términos temáticos. Estas esferas, la formal y la temática, funcionan como elementos de relación con la audiencia, ya que los individuos receptores se identifican con ciertos modos de representación y con la significación potencial del relato. Además, la tendencia dentro de las series de ficción es alejarse de los temas grandilocuentes. En las series de ficción, "la verosimilitud, fruto de la investigación y documentación, se convierte en el factor que da realismo y credibilidad" (Cabezuelo Lorenzo, González Oñate y Fanjul Peyró, 2013: 8). Los discursos ficcionales que se están forjando en los últimos años están más en consonancia con la crítica social y la construcción de personajes más humanos, más cercanos a la realidad miserable que comparten muchos de los individuos que pueblan el planeta. Quizá por ello se tiende a calificar a estas series de 
culto, atendiendo a su capacidad para mostrar ambientes más reales, menos amables y más cercanos. No obstante, este tipo de productos audiovisuales se aleja de los estándares ideológicos de la cultura imperante y genera una nueva visión sobre ciertos temas controvertidos y que no habían sido mostrados en las pantallas hasta el momento. Además, se trata de productos de calidad. Como explica Thompson (1996) en su análisis sobre las series de ficción televisiva de los años ochenta y noventa, la calidad de estos relatos está estrechamente relacionada con el poso crítico que evidencian, con los ambientes sociales a los que hacen referencia. Como sabemos, la última década ha sido denominada la tercera edad dorada de la ficción televisiva, debido a que gran parte de las series de producción estadounidense funcionan con un gran número de indicadores de calidad y, por ello, se han erigido en paradigmas de la calidad en estas formas narrativas. Las grandes empresas de producción audiovisual como HBO, CBS, NBC, ABC o ShowTimes han apostado por estos formatos originales y han dado lugar a una revolución en la construcción ficcional, de ambientes, personajes, tramas, etc. Los nuevos relatos han hecho aflorar tramas complejas, digresiones temporales, personajes contradictorios que en la mayoría de casos tienen como fin trastocar los roles tradicionales y conectar con una audiencia que se valora a sí misma como un conglomerado de individuos inteligentes y más preparados y formados audiovisualmente que las generaciones anteriores.

Como vamos a desarrollar en el presente trabajo, un ejemplo de serie de ficción como la que estamos dibujando es Orange is the new black, emitida por primera vez el 11 de julio de 2013 a través de la novedosa plataforma audiovisual de pago Netflix (en España se emite por medio de Canal Plus). Se trata de una serie que podemos encuadrar dentro de los productos ficcionales de calidad, siguiendo las consideraciones de Cascajosa (2006: 23-33). De este modo, esta serie aglutina todos los indicadores de calidad de la mayoría de series de las grandes productoras: la búsqueda de creadores consagrados, la innovación en el género y en la estructura narrativa, la importancia de los canales de pago y la emergencia de tabúes en la argumentación. Como explica Feuer (2007: 145), los indicadores de calidad pueden ser diferentes en cada serie, pero la mayoría de ellos se repite, como ocurre en todas las producciones de la afamada HBO. Especial atención vamos a prestar a través del estudio propuesto a los ámbitos mostrados por Cascajosa y por Feuer. De modo que el objetivo principal del trabajo será forjar una visión antropológica sobre Orange is the new black como serie de ficción que apuesta por la innovación en el género, por una novedosa estructura narrativa y por la manifestación o puesta en escena de tabúes en la argumentación y que confiere una mayor notoriedad a ciertas realidades que suelen ser veladas por la cultura imperante y por los poderes fácticos. 


\section{Se acabó el sueño americano}

Todos los productos audiovisuales cumplen, por sí mismos, una función pedagógica. Lo pretendan o no, las películas y las series de televisión nos influyen en nuestras creencias, nuestros pensamientos y en nuestros modos de comportamiento social. En mayor o menor medida, los grandes directores y guionistas de la historia han desarrollado relatos con un gran componente ético y moral. No obstante, las grandes producciones audiovisuales de los años cuarenta, cincuenta y sesenta del siglo veinte han ofrecido lecciones sobre cómo vivir y desenvolverse en sociedad. Por citar uno de estos numerosos ejemplos, es posible recordar películas como The fountainhead (1949), de King Vidor, un drama romántico protagonizado por Gary Cooper y Patricia Neal en el que se muestran las supuestas bondades del individualismo, del trabajo duro, de la construcción individual de la persona en el mundo contemporáneo y del liberalismo, con una cierta crítica a los nuevos modos de proceder que se alejan del liberalismo clásico; dicho de otro modo, la crítica que plantea Vidor se centra en que la sociedad del momento está abandonando las ideas del liberalismo clásico por la esclavitud de ciertas formas de comportamiento social y económico que pueden asemejarse al neoliberalismo emergente. En cualquier caso, se trataba de narraciones audiovisuales en las que se mostraba al ciudadano ejemplar, un individuo con la capacidad de forjarse un futuro de éxito a base de trabajo duro y de aprovechar las oportunidades que se encuentra en su vida. Pero a partir de los años sesenta y, sobre todo de los años setenta del siglo veinte, las dinámicas de representación y la construcción de personajes y ambientes comienza a cambiar. Es la llamada segunda edad dorada de la ficción en cine y televisión.

En mayor o menor medida, las narraciones audiovisuales presentan un componente mimético. Es decir, los relatos del cine y la ficción televisiva muestran trozos de vida, más o menos aderezados, más o menos creíbles. Como argumenta SánchezEscalonilla (2009: 51), "siempre que se construye y narra un relato ficticio, el autor parte de la experiencia real para recrear aspectos de la vida". Por tanto, en toda narración audiovisual es necesario inyectar una gran dosis de verosimilitud, a pesar de que dichas construcciones narrativas sean ficticias. En este ámbito, las series de ficción de la última época han apostado por dibujar vidas muy reales. Así, las narraciones actuales tienden a abandonar los personajes titánicos y gloriosos. Los superhombres y supermujeres son ahora los de carne y hueso, los que se parecen a la mayoría de individuos, pero que cuentan historias trepidantes, que podrían ocurrirnos a nosotros. De modo que las series actuales apuestan por los antihéroes.

La figura del antihéroe es fundamental para entender las nuevas formas narrativas. Los personajes ideales o modelos ya no son protagonistas en las nuevas series de ficción. Al contrario, la vuelta a la realidad es cada vez más acuciante y se muestran 
situaciones que no esconden las miserias del mundo contemporáneo. Muchas producciones de ficción intentan ofrecer notoriedad a hechos sociales, dramáticos en muchas ocasiones, que no tienen cabida en los informativos. La intención de algunas de estas series es conferir visibilidad a ciertos relatos sociales reales; probablemente más reales que muchas de las noticias que leemos o vemos a menudo en los diarios o en la televisión. Las nuevas series plantean personajes que se desenvuelven en una sociedad contaminada, caracterizada por una crisis económica profunda que obliga a las sociedades a reformular sus objetivos vitales $y$, por ende, sus tramas vivenciales. Ya no tienen cabida los quiméricos héroes.

Los nuevos relatos ficcionales muestran personajes verosímiles. Son figuras discursivas opuestas a los tradicionales héroes y que llevan a cuestas visiones negativas, quizá más realistas, de la sociedad que los rodea, de su funcionamiento y de las posibilidades futuras. No obstante, son perspectivas que chocan con el sistema imperante. Los nuevos protagonistas son personajes desencantados con la sociedad y con sus miembros, debido a las malas experiencias vividas. Son antihéroes, protagonistas que no encuentra su lugar dentro de la colectividad y se sienten rechazados. En este sentido, Vogler (2002: 72) realza una clasificación bastante original sobre los antihéroes. A grandes rasgos, en los diferentes relatos de ficción nos podemos encontrar con dos tipos fundamentales de antihéroe:

- Los antihéroes que se parecen a los héroes convencionales pero con un fuerte toque de cinismo o arrastran alguna herida.

- Los héroes trágicos, quienes no son de nuestro agrado y cuyas acciones podemos incluso deplorar pero que nos resultan simpáticos.

Pronto nos percatamos de que, si seguimos esta clasificación, podemos reconocer a ciertos personajes propios de la narración ficcional en televisión y que pueden ubicarse dentro de esta ordenación (Álvarez Berciano, 1999). Muchos de ellos forman parte de la ficción televisiva contemporánea. Walter White (Breaking Bad), Tony Soprano (Los Soprano), Gregory House (House) o Rust Cohle (True Detective) son antihéroes o personajes oscuros representados de un modo arquetípico. Para la ficción televisiva estadounidense contemporánea, en gran medida, ya no son válidos los argumentos excesivamente tópicos y los finales previsibles, rebosantes de fortuna. La novedad es la utilización del fracaso como eje narrativo, debido quizás a que se trata de un hecho patente en las sociedades actuales. El sueño americano ha dado paso al fracaso americano.

Orange is the new black muestra sin tapujos este fracaso del sueño americano. Muestra la decadencia de unos personajes que sufren el menosprecio de una sociedad 
posiblemente cruel con un colectivo tradicionalmente maltratado, las mujeres. Además, habla sin caer en el morbo de temas controvertidos como la bisexualidad (mostrada por medio del personaje principal), el lesbianismo, la represión sexual, el poder y la corrupción policial y las injusticias del sistema de prisiones estadounidense, más propio de países subdesarrollados.

\section{Método de análisis}

Para la consecución del objetivo de investigación propuesto vamos a desarrollar un análisis de la primera temporada de la serie, compuesta por trece episodios de unos sesenta minutos cada uno. El método de trabajo se fundamenta en el análisis cualitativo del discurso, con especial atención a diveros parámetros narrativos que nos ayudarán a descifrar la perspectiva antropológica que traza la serie. Como hemos comentado, Orange is the new black habla de una historia real, una historia de fracaso y de supervivencia en una sociedad posiblemente más cruel de lo que podamos pensar. El argumento, las tramas y las relaciones que tienen entre sí los diferentes personajes nos hablan constantemente de situaciones límite en las que uno debe elegir. Son situaciones de bien y de mal en las que probablemente hay una gradación mayor que en un simple análisis maniqueísta. Por todo ello, la serie también nos habla de elementos éticos y morales que pretendemos hacer aflorar.

Siguiendo todas estas consideraciones, vamos a desarrollar un análisis cualitativo de la narración en la que vamos a atender a los siguientes parámetros:

- Construcción de los personajes:

- Definición de personajes: fundamentalmente nos centramos en la caracterización de los personajes; es decir, en su personalidad y en su carácter, en su presencia física, en la forma en la que aparecen en la escena, en la acción que desempeñan.

- Relaciones entre personajes: nos referimos a las relaciones que se desarrollan entre los distintos personajes principales. Al ser una serie que podríamos llamar coral, el análisis de la relación entre protagonista es fundamental para extraer conclusiones en torno a la construcción antropológica de la historia.

- Componentes de la narración:

- Perspectiva o cosmovisión de la protagonista: la visión del protagonista se podrá percibir a través de la definición de los personajes y de sus relaciones con los demás actantes del relato a través del análisis de toda la temporada.

- Ambientes o escenarios: hacemos alusión preferentemente al cronotopo, como constructo imaginario en el que confluyen las ideas de espacio y tiempo (García López y Hellín Ortuño, 2014: 759-769). 
- Estructura de la acción narrativa: en esta categoría analizamos fundamentalmente cómo se desenvuelven y relacionan las categorías anteriores de la narración y cómo se gestionan en el relato el tiempo y el espacio. Antendiendo a la naturaleza de la serie, atendemos especialmente a las anacronías en forma de analepsis o flashbacks.

- Tono del discurso: el tono es el carácter del discurso, su matiz dramático o humorístico que va a ayudar en la construcción de la perspectiva antropológica de la serie; el tono nos ofrece información sobre el modo intelectual, ético-moral y sociopolítico del relato.

Como se evidencia en los elementos seleccionados para el análisis del relato, se trata de componentes que nos proporcionan datos sobre cómo se relacionan los personajes, sobre la influencia del contexto o del ambiente en el que se relacionan y sobre los efectos de sus conductas. De manera que estamos valorando en todo momento una visión antropológica del relato. De modo que los resultados que vamos a extraer de este análisis puramente cualitativo nos ofrecerán información sobre el fundamento antropológico de la serie (fundamentalmente de sus personajes y de las relaciones que se producen entre ellos) y sobre su legado ético y moral, que servirá para conectar con la audiencia y para ofrecer una nueva perspectiva sobre una situación probablemente desconocida por la mayoría de receptores.

\section{Resultados y discusión}

Orange is the new black es una creación de Jenji Kohan, creadora de Weeds, considerada una de las dramedias de mayor calidad de los últimos años. También ha sido productora de Las chicas Gilmore y guionista de Tracey takes on, una serie ganadora del Emmy producida por HBO, considerada como una de las series de culto de la última década. El relato es un drama con tintes cómicos producida por Lionsgate Television (Mad Men, Boss, Nurse Jackie, Nasvhville) para la plataforma de pago Netflix y basada en el libro de Piper Kerman Orange is the new black: crónica de mi año en una prisión federal de mujeres. Con esta obra, la autora quiso plasmar cómo pasó de una vida de éxito como alta ejecutiva de una importante empresa a ser detenida por un asunto de drogas comitido diez años antes. En un instante pasó de vestir con traje negro lujoso a enfundarse la típica y estereotípica vestimenta naranja de las cárceles norteamericanas. Kerman relata sus vivencias reales durante su ingreso en la cárcel de mujeres. El libro pronto se convirtió en un best-seller. Igualmente, Keller participó activamente en la construcción del guión de la serie como coordinadora y como productora ejecutiva.

La originalidad principal de esta serie de ficción es que es la primera narración ficcional que retrata el ambiente de las prisiones de mujeres en Estados Unidos. 
Además, un signo distintivo del relato audiovisual es su estructura narrativa, ya que se utiliza de un modo novedoso la técnica de flashbacks concatenados y que van mostrando de una forma coral las vidas de las reclusas protagonistas antes de entrar en la cárcel. Por otro lado, la serie ha sido dirigida por un equipo de directores y realizadores especializados en el subgénero dramedia. En este elenco han participado Michael Trim (Weeds), Uta Briesewitz (Hung), Phil Abraham (Mad Men), Matthew Pen (Damages) o la conocida Jodie Foster, quien dirige el capítulo tres con el morbo añadido que supone su orientación sexual declarada. Pero la innovación de la serie no se queda en el propio argumento. Una de las singularidades es que la plataforma televisiva Netflix puso la serie completa a disposición de sus clientes desde el primer momento. Esta estrategia ha sido repetida por Canal Plus en España, a través de su plataforma virtual Yomvi, que habilitó los trece capítulos de la primera temporada desde el primer día del estreno en nuestro país (ambas plataformas televisivas repiten la operación con la segunda temporada de la serie, en junio de 2014).

\subsection{Los personajes de Orange is the new black}

Los personajes de la serie son lo que suele denominarse en los estudios de narrativa audiovisual personajes redondos. Esto es, son protagonistas complejos y con una personalidad rica, que ayudan a la construcción de un relato constantemente sorprendente. Son personajes que, aun no aglutinando un excesivo número de características, consiguen que la situación narrativa mantenga al receptor en constante alerta. Como escribe McKee (2002: 449), "decorar a un protagonista con muchas características no abre al personaje ni atrae empatía".

Como hemos comentado, la serie relata las vivencias reales de Piper Kerman, lo que condiciona tanto la determinación de la personalidad de los personajes como la potencial interpretación del receptor. Además, se trata de una serie con un reparto coral, lo que confiere una mayor importancia a todos los personajes, a pesar de que la acción principal recae en la protagonista, Piper Chapman (Piper Kerman en la ficción).

Piper vive en la ciudad estadounidense de Connecticut, en el noreste del país. Su vida parece estable y ocupa un rol social más o menos importante, dentro de sus relaciones familiares y sociales. Está prometida con un prototipo de escritor de familia bien, su novio Larry Bloom, y todo marcha viento en popa. La estabilidad, por tanto, es una de las características fundamentales de su existencia, ya que su vida transcurre de manera acomodada y está acostumbrada a que sus expectativas se vayan cumpliendo. Pero un hecho del pasado que brota de repente dará al traste con ese equilibrio emocional. Años atrás, Piper había delinquido con drogas junto a su compañera narcotraficante Alex Vause, con la que mantenía una relación amorosa, y 
ahora es acusada de un delito de contrabando de sustancias estupefacientes. Piper no pone trabas en el proceso judicial, pretendiendo con ello cerrar de una vez por todas con la etapa oscura de su pasado. De modo que es procesada e ingresa en la cárcel de mujeres de Litchfield, en Nueva York, por un año.

Este argumento, aparentemente tópico e incluso trivial, se convierte en realidad en una vía narrativa para poner de manifiesto ciertas conductas de una sociedad supuestamente modélica que, al menos, dan para reflexionar sobre el abuso de poder, sobre la sexualidad $y$, en definitiva, sobre la moralidad de una sociedad que se piensa libre pero que anda limitada constantemente por las barreras ideológicas impuestas por las esferas hegemónicas. Podemos decir que este es el centro de un relato que se construye a través de las relaciones existentes entre los distintos personajes. Sobre Piper, su personalidad, sus conductas y sobre la evolución de estas dos categorías se va generando un discurso sobre una visión antropológica de la vida norteamericana. Dicho discurso únicamente es posible gracias a las relaciones que Piper mantiene en la prisión con los demás personajes. A continuación planteamos la caracterización de los diferentes participantes del relato.

- Piper Chapman (interpretada por la actriz Taylor Schilling): se trata del personaje central sobre el que gira la serie. Piper concentra una disyuntiva ética y moral entre el bien y el mal, pero que no se fundamenta en un discurso maniqueísta. Es decir, pronto se da cuenta Piper de que no todo es negro o blanco en la vida, de que no siempre podemos juzgar al resto de personas mediante los calificativos de buena o mala, sino que todo depende de las circunstancias. La moral que concentra Piper es, por tanto, contextual. Su vida en la cárcel no comienza bien, ya que se siente totalmente desubicada y tiene problemas para tomar las decisiones correctas en los momentos justos. Al principio tiende a evitar cualquier tipo de problemas, aunque se percatará pronto de que en muchas ocasiones es necesario tomar la iniciativa y posicionarse. En el transcurso de la serie su personalidad se irá modificando, no dudará en enfrentarse a sus enemigos si es necesario e irá mejorando sus artes de manipulación para conseguir sus objetivos.

- Alex Vause (interpretada por la actriz Laura Prepon): es la antigua novia de Piper y quien la introduce en el mundo de las drogas y del narotráfico. Alex, al contrario de lo que ocurre con Piper, nació en una familia humilde y siempre tuvo que lidiar con la discriminación propia de su condición social. También es recluída en la prisión de mujeres de Litchfield, junto a Piper. Alex es una persona inteligente, que se sabe mover muy bien en el ámbito de la calle y conoce perfectamente cuál es su rol en la cárcel. Es consciente de que no debe relacionarse mucho con las demás reclusas, aunque no tiene miedo de enfrentarse a ellas si lo cree necesario. Alex representa un vehículo emocional para Piper, ya que en ocasiones descifra los sentimientos de esta, lo que ayuda la interpretación del receptor sobre la personalidad de la protagonista. 
Aparentemente, Alex muestra una personalidad mucho más fuerte que Piper, pero en realidad es frágil. No obstante, años atrás, cuando Piper rompe con ella, Alex comienza a consumir heroína, a pesar de que después consigue atajar la adicción.

- Galina Reznikov, "Red" (interpretada por la actriz Kate Mulgrew): trabaja en la prisión de mujeres y dirige la cocina. En su vida anterior regentaba un restaurante junto a su marido. Su rol dentro de la prisión es peculiar, ya que actúa como una madre para varias reclusas. Tiene una personalidad fuerte, quizá curtida en sus relaciones anteriores con la mafia rusa. Su relación con Piper es importante, ya que gracias a su dureza la protagonista consigue percatarse de cómo debe comportarse dentro del ambiente carcelario. La mano dura de "Red" se ve compensada con su figura maternal. Sin embargo, no cabe duda de que maneja un rol de poder y representa, en cierta medida, cómo funciona en la vida real la sociedad, mediante relaciones de dominación y sumisión.

- Suzanne Warren, "Crazy eyes" (interpretada por la actriz Uzo Aduba): es una reclusa emocionalmente inestable, que siempre está intentando buscar el apego de las demás reclusas. Es, claramente, una enferma mental, si bien no podemos determinar el tipo de enfermedad concreta que manifiesta. Al principio intenta tener una relación con Piper, aunque esta la rechaza. A pesar de su inestabilidad emocional, "Crazy eyes" se va dando cuenta del cambio que está sufriendo Piper en su personalidad y llega a pensar que se está conviertiendo en una mala persona.

- Tiffany Dogget, "Pennsatucky" (interpretada por la actriz Taryn Manning): se trata de una fanática cristiana que ha sido encarcelada por disparar a una enfermera por haberle practicado un aborto. A pesar de su extremismo ideológico aparente, es una chica confundida que encuentra en el radicalismo cristiano una solución a sus problemas momentáneos. Su relación con Piper es tortuosa, no le gustan las lesbianas debido a su posición religiosa y le hace la vida imposible. De algún modo, "Pennsatucky" persigue salvar el alma de Piper y por ello intenta manipularla.

- Sam Healy (interpretado por el actor Michael Harney): es un funcionario de prisiones cuya posición será especialmente relevante dentro del grupo. Al comienzo, Healy ofrece su ayuda como trabajador social a Piper. Sin embargo, cuando se percata de la condición sexual de Piper, le da la espalda y se convertirá en una especie de enemigo al que evitar, debido a su agresividad. Representa una figura de poder que pretende imponer su pauta ideológica a las demás personas, especialmente en lo referido a la homosexualidad.

- George Mendez, "Pornstache" (interpretado por el actor Pablo Schreiber): es posiblemente el representante del mal en la prisión. Se trata de un funcionario de prisiones cuyo único objetivo es ejercer el mal y someter al resto de 
individuos. Todas sus acciones son gratuitas y responden esencialmente a la corrupción por la corrupción. Su abuso de autoridad es constante, vende drogas y es conocido dentro de la prisión por su tendencia a abusar sexualmente de las reclusas. No influye únicamente a Piper, sino que todo el colectivo de reclusas se sienten amenazadas por él. Como ocurre en el resto de sociedades, en su mayoría, el miedo ejerce una presión constante en los individuos sometidos por los poderes hegemónicos y se convierte en un determinante de las conductas sociales.

- Larry Bloom (interpretado por el actor Jason Biggs): es el prometido de Piper. Pretende ser escritor y su posición social es acomodada. Está convencido de que su relación con Piper no se verá afectada, a pesar del período que tiene que pasar ella en prisión. Sin embargo, con la entrada en prisión de Alex volverán los fantasmas del pasado y Bloom comenzará a desconfiar de su novia. Es una persona fuertemente influida por sus padres, que le aconsejan la ruptura con Piper.

Durante los trece episodios de la primera temporada de la serie podemos ver cómo confluyen otros personajes con mayor o menor presencia, tales como las reclusas Claudette, Nichols, "Taystee", Daya, "Big Boo", Burset, Washington o Morello. Sin embargo, la relación de estas con Piper no proporciona información sobre la perspectiva antropológica que representa la figura de la protagonista. Es importante la existencia de dos bandos diferenciados entre las reclusas, las de color negro y las de origen latino. No obstante, se trata de una representación de los dos grandes grupos sociales con una mayor tasa de discriminación en Estados Unidos.

\subsection{Los componentes de la narración}

La perspectiva de la protagonista, fuertemente influida por las relaciones sociales que mantiene con los personajes que hemos intentado retratar en el epígrafe anterior, plantea una visión antropológica novedosa sobre la vida en las cárceles de mujeres en Estados Unidos. Además, esta cosmovisión se configura en una nueva perspectiva crítica que pone de relieve las siguientes características fundamentales: los abusos de poder en la sociedad; la dificultad que tienen los individuos que forman parte de las clases sociales bajas de poner fin a su discriminación y de salir de su situación; y la problemática de la homsexualidad y de su aceptación en las sociedades contemporáneas, una problemática que no debería ser tal en pleno siglo XXI.

El contexto que muestra la serie, los ambientes, los escenarios, contribuyen a reforzar el espíritu crítico del discurso. Todo ello a pesar de que no se percibe directamente un relato sobre lo bueno y lo malo, sobre lo ético y lo no ético, sobre lo moral y lo no moral. Aún así, la concatenación de contextos de discriminación, abusos de poder y 
sexualidad reprimida nos habla sobre la mediocridad de la ideología imperante, que se impone sobre otras posibles visiones o perspectivas vitales. La cárcel, que es el escenario principal, pasa de ser un centro de reinserción social a constituirse en un antro donde los acontecimientos abocan a la mayoría de individuos a sobrevivir, a pensar en sí mismos y olvidarse de un valor fundamental para poder convivir dignamente, la mutualidad. La serie plantea una serie de lugares que han permanecido ocultos en nuestro imaginario, quizás por la dinámica social impuesta.

La acción narrativa es original, ya que la situación anterior de los distintos personajes y las experiencias actuales se relacionan por medio de flashbacks o analepsis. Esto es especialmente importante, ya que ayuda al receptor a forjarse una panorámica profunda sobre la evolución de los personajes, sobre sus situaciones anteriores y sobre las vivencias del momento en la cárcel. Pronto nos podemos percatar que la prisión no es la solución a los problemas de la sociedad. Peor aún, cuando hablamos de vidas que podemos calificar de normales, en la cárcel se convierten en vidas sostenidas por la disyuntiva continua entre el bien y el mal; en la supervivencia, por consiguiente. Los flashbacks como recurso narrativo son fundamentales en el relato de esta serie, porque lo importante es conocer la visión antropológica. Lo primordial es conocer cómo las personas que vienen de contextos deprimidos generalmente permanecen en esa situación, saber que los individuos que son corruptos lo son porque ya lo eran anteriormente y percatarse de que los sujetos que vivían de manera aparentemente acomodada pueden hundirse en la miseria en unos instantes. Y lo peor, ciertas instituciones sociales creadas para mejorar nuestras vidas, como las cárceles, sólo logran imponerse como medios de sumisión y generación de miedo.

El otro componente original de esta serie es la gama tonal del relato. No se puede negar que el argumento es totalmente dramático, atendiendo a los hechos que cuenta. Pero el tono tiene un toque cómico que mantiene despierta la atención del receptor. La audiencia empatiza con el relato porque el tono mantiene una carga emotiva suficiente para empatizar con la protagonista, fundamentalmente, y con algunos de los personajes principales. Dicho de otro modo, lo que permite al receptor no abandonar la serie debido a su crudeza es la carga sentimental y el matiz jocoso con el que transcurren algunas secuencias.

\section{Conclusiones}

Orange is the new black plantea una perspectiva antropológica de las cárceles, con especial atención a las dedicadas exclusivamente a mujeres. Se trata de una visión antropológica porque relata aspectos sociales y culturales de esos ambientes. No es un discurso de lo bueno y lo malo, pero sí lo es de una ética no universal. Porque 
como vemos en la evolución de la protagonista, Piper, muchas de sus acciones y muchos de los efectos que estas provocan son únicamente fruto del afán por sobrevivir, por conseguir salir adelante. La cárcel es un universo paralelo en el que los problemas más livianos o insignificantes se vuelven insoportables para Piper. La prisión se convierte en un high school. La protagonista también echa de menos cosas que en su vida anterior a su ingreso en el centro carcelario no tenían importancia, como sabores, olores,sensaciones. Todo le ha sido negado durante su estancia allí.

Ante los abusos de poder y la corrupción policial en lugares como la prisión que se muestra en la serie, tal vez más usual de lo que la mayoría puede pensar habitualmente, las personas deben elegir entre lo malo y lo peor. Esto es, en ocasiones, el contexto (la hostilidad, el miedo, la presión ejercida por los abusos de las autoridades, etc.) no permite elegir salidas que no den lugar a efectos colaterales. Como vemos en la narración, a veces lo que nos rodea delimita nuestras elecciones y el concepto de libertad se convierte en un constructo cultural vago.

Los tres ejes socioculturales de esta serie de ficción son la homosexualidad (concretamente, el lesbianismo), la corrupción y el poder. La sociedad occidental ha impuesto una visión ideológica de cada uno de estas tres categorías y, por tanto, la posición mayoritaria sobre cada una de ellas deja poco margen para la crítica y para la relatividad. La tradición platónica que impera en nuestro modo de pensamiento ejerce una influencia determinante a la hora de considerar las categorías axiológicas como universales. Sin embargo, lo que Orange is the new black pone de manifiesto es que lo que a veces se considera de una manera absoluta sobre la homosexualidad o sobre las personas marginadas solamente tiene sentido cuando se pone en relación con su contexto o en función de las relaciones que se dan entre la persona que actúa de una cierta manera y las acciones de los demás en un ambiente concreto.

\section{Bibliografía}

Álvarez Berciano, R. (1999). La comedia enlatada. De Lucille Ball a Los Simpson. Barcelona: Gedisa.

Bauman, Z. (2001). La postmodernidad y sus descontentos. Madrid: Akal.

Bordwell, D. (2007). El arte cinematográfico. Barcelona: Paidós.

Cabezuelo Lorenzo, F.; González Oñate, C. \& Fanjul Peyró, C. (2013). Los paisajes del sueño americano: escenografía de "Mad men". Revista de Comunicación de la SEECI, 32, 1-11.(DOI: http://dx.doi.org/10.15198/seeci.2013.32.1-11) 
Cascajosa Virino, C. C. (2006). No es televisión, es HBO: la búsqueda de la diferencia como indicador de calidad en los dramas del canal HBO. ZER, 21, 23-33.

Feuer, J. (2007). HBO and the Concept of Quality TV, en McCabe, J. \& Akass, J. (ed.). Quality TV. Contemporary American Television and Beyond. London: I. B. Tauris.

García López, J. \& Hellín Ortuño, P. A. (20014). Cronotopos y estereotipos de la ficción publicitaria. Un análisis sobre la identificación del receptor con la ficción publicitaria. Historia y Comunicación Social, 19, 759-769. (DOI: http://dx.doi.org/10.5209/rev_HICS.2014.v19.45000)

McCabe, J. \& Akass, J. (ed.) (2007). Quality TV. Contemporary American Television and Beyond. London: I. B. Tauris.

Sánchez-Escalonilla, A. (2009). Estrategias de guión cinematográfico. Barcelona: Ariel.

Savater, F. (1992). La tarea del héroe. Barcelona: Destino.

Thompson, R. J. (1996). Television's Second Golden Age: From 'Hill Street Blues' to 'ER'. New York: Continuum.

Vogler, C. (2002). El viaje del escritor. Las estructuras míticas para escritores, guionistas, dramaturgos y novelistas. Barcelona: Ma Non Troppo. 


\section{AUTORES:}

\section{Javier García López}

Profesor Adjunto en la Universidad a Distancia de Madrid, donde imparte las asignaturas Teoría de la Publicidad, Opinión Pública e Historia de la Comunicación Social. Anteriormente ha sido profesor en la Universidad San Jorge de Zaragoza, en el área de Publicidad. Obtuvo el doctorado en Ciencias de la Comunicación y la licenciatura en Publicidad. Es Master Universitario en Crítica y Argumentación Filosófica, especialista en Epistemología y Gnoseología, así como en Comunicación Institucional y de la Empresa. Autor de diversos artículos científicos, capítulos de libro y monografías.

\section{Alicia López Balsas}

Guionista en el departamento de Autopromoción de Canal Plus España. Es autora de diversas campañas, spots y guiones para los diferentes canales de la cadena de pago. Anteriormente ha sido redactora creativa en Draft FCB. Es licenciada en Publicidad, Master en Creatividad Publicitaria por Miami Ad School y Master Universitario en Cine, Televisión y Medios Interactivos por la Universidad Rey Juan Carlos. Es autora de artículos de investigación y capítulos de libro sobre cine, televisión y medios audiovisuales. 